\title{
Relating induction time and metastable zone width
}

Huaiyu Yang ${ }^{\&+}$, Alastair Florence ${ }^{+}$

\&Department of Chemical Engineering, Imperial College London, London, UK

${ }^{+}$Continuous manufacturing and crystallization (CMAC), TIC, University of Strathclyde, Glasgow, UK

\begin{abstract}
A relation between induction time and metastable zone width in cooling crystallization has been developed based on the correlation between temperature and supersaturation with induction time in Classical Nucleation Theory. By this relation the nucleation times in linear cooling experiments and the induction times at constant temperature can be estimated from each other, i.e. estimating metastable zone widths from experimental induction times or interfacial energy and the preexponential factor from metastable zone widths. 120 induction times and 192 metastable zone widths of ascorbic acid in water have been determined, together with several systems reported in the literature, have been investigated to compare the estimated values of metastable zone width / induction time with experimental values, respectively. The estimated metastable zone widths are fairly consistent with the experimental values. The differences between experimental literature values of metastable zone widths with the estimated values using the literature induction times range from $0.1 \mathrm{~K}$ to $10 \mathrm{~K}$ with an average of $2.5 \mathrm{~K}$. For two systems (paracetamol in ethanol and salicylic acid in ethyl acetate) estimated and experimental results are of very good consistency with the average uncertainty only about $5 \%$. More accurate extrapolations of the induction times from metastable zone widths have been investigated. The potential utilities of this approach in crystallization research and process understanding are discussed.
\end{abstract}


Key words: metastable zone width, induction time, Classical Nucleation Theory, cooling crystallization, cooling rate

\section{Introduction}

Nucleation is an ubiquitous phenomenon and process in nature by which a new phase is formed, and it is of direct relevance to many industrial processes ${ }^{1}$. Crystallization is the key step in the manufacture of most active pharmaceutical ingredients and small organic compounds and has a governing influence on the crystal product attributes ${ }^{2}$. Despite its importance however crystal nucleation remains poorly understood ${ }^{3}$.

The nucleation behaviours are usually characterized by measurements of induction time ${ }^{4}, \mathrm{t}_{\text {ind }}$, or metastable zone width, $\mathrm{MSZW}^{2,5}$. MSZW is the temperature difference between the saturation temperature and the nucleation temperature observed at a constant cooling rate. The MSZW is a measure of nucleation under polythermal conditions and has practical applications for design of crystallization processes, helping to select an ideal seeding point for a crystallization process ${ }^{2}$. Nucleation time, $t_{\mathrm{mszw}}$, in a MSZW experiment can be defined as the time between the solution reaching saturation and nucleation being observed/detected during cooling, when the supersaturation increases with decreasing temperature. In polythermal experiments with linear cooling rates, several approaches have been developed for example by $\mathrm{Nyvlt}^{6}$, Kubota ${ }^{7}$ and Sangwal ${ }^{8}$ based on an emperial nucleation rate equation: $J=b_{1}(\Delta T)^{b_{2}}$. MSZW data have been reported for many systems including acylanilides in aqueous ethanol ${ }^{9}$, paracetamol in water ${ }^{10}$ or in ethanol ${ }^{11}$, benzoic acid in ethanol-water mixtures ${ }^{12}$ and co-crystals of benzoic acid / isonicotinamide in $95 \%$ ethanol ${ }^{13}$. Recently the relation between MSZW and induction times was investigated by using probability theory to estimate nucleation rates ${ }^{8,14-20}$. 
Induction time, $\mathrm{t}_{\text {ind }}$, is measured under isothermal conditions and is defined as the time period from the solution reaching a constant temperature (supersaturation) until observing/detecting the nucleation. In isothermal experiments, interfacial energy and pre-exponential factor can be determined using the classical nucleation theory equation ${ }^{21-24}: J=A \exp \left(-\frac{\Delta G_{c}}{k T}\right)$. This approach has been used to provide further understanding of the solute-solvent interactions ${ }^{25}$, as well as transition state ${ }^{26}$, solvation shell ${ }^{4}$ and desolvation process ${ }^{27}$. The relation between induction time and MSZW in supersaturated solutions has been compared ${ }^{28}$, however the relation between MSZW, interfacial energy and pre-exponential factor has not been established ${ }^{29-30}$. The motivation for this study is therefore to address this gap and further understand nucleation thermodynamics and kinetics during MSZW experiments.

The relation between the induction time, measured in isothermal experiments, and the nucleation time, measured in polythermal experiments, was derived from classical nucleation theory equation by using the pre-exponential factor and the critical nucleation potential ${ }^{31}$. The critical nucleation potential, $\mathrm{N}$, is a constant parameter describing the propensity for the system to nucleate and is independent of cooling rate and supersaturation. Recently, Shiau proposed an alternate interpretation to nucleation potential, defining a critical nucleation density that enables observation of nucleation ${ }^{32-35}$. Using the nucleation potential, MSZWs at different cooling rates estimated from published experimental induction time values show good correspondences to experimental MSZW values. This indicates that polythermal MSZW measurements can provide details on the role of solute-solvent interactions and kinetics during cooling crystallization. This relation can provide understanding of the influence of different process conditions including cooling rate ${ }^{36}$, saturation temperature ${ }^{37-40}$, stirring rate ${ }^{41}$ and solution volume ${ }^{14-15}$ on the nucleation. In addition, this relation could provide the basis to identify the suitable temperature range for a seeded 
crystallization in order to help control size distribution and avoid uncontrolled primary nucleation during cooling crystallization. Specifically, the ability to estimate MSZWs at different cooling rates based on a limited number of induction time experiments could minimise the time and material requirements during the design of cooling crystallization processes.

In this work, the induction time and MSZW of L-ascorbic acid in water have been experimentally determined. A method is proposed to estimate median induction times from the measured median MSZWs. The estimated values of induction time and MSZWs in the aqueous L-ascorbic acid system, as well as in other systems reported in the literature, in which both induction time and MSZW data are reported, are compared with the experimental values, respectively. The interfacial energy and pre-exponential factor are extrapolated from the MSZW with this relation.

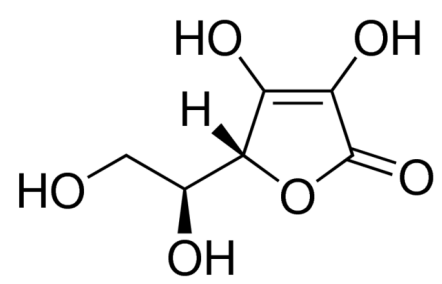

Figure 1 Molecular structure L-ascorbic acid

$\mathrm{L}$-ascorbic acid is a form of vitamin $\mathrm{C}$ and is an antioxidant ${ }^{42}$. Its molecular structure is shown in Figure 1 , and it has only one reported polymorph ${ }^{43}$. It is soluble in water with reported solubility of $0.29 \mathrm{~g} / \mathrm{g}$ water at $20{ }^{\circ} \mathrm{C}^{44}$. In industry it is usually purified by multistage batch crystallization from water ${ }^{45}$.

\section{Theory}

Critical nucleation potential ${ }^{31}$, describes the potential for the nucleation of a system whereas the accumulated nucleation potential describes the potential for nucleation given the history of the 
supersaturated state. For example, in cooling crystallization, nucleation potential accumulates when supersaturation is generated. Higher levels of supersaturation and longer time period lead to larger accumulated nucleation potential. The closer gap between the total accumulated nucleation potential with the critical nucleation potential is, the larger chance of occurring nucleation is. Nucleation potentials in cooling crystallization with two kinds of simple temperature profiles are presented in this part, first is the induction time experiments (with constant temperature), and second is MSZW experiments (with linear cooling rate).

In classical nucleation theory, the induction time, $t_{\text {ind }}$, consists of three parts ${ }^{5}$ : a relaxation time or transient period, $t_{\mathrm{r}}$, the time required to nucleate, $t_{n}$, and the growth time for a nucleated crystal to be detected, $t_{\mathrm{g}}$. If the relaxation time and the growth time are assumed to be negligible ${ }^{21-24}$, the induction time, $t_{\text {ind }}=t_{\mathrm{r}}+t_{n}+t_{g} \approx t_{n}$, is inversely proportional to the nucleation rate ${ }^{2}, J$, in a solution with volume $V$. Combining the Arrhenius equation of nucleation rate in Classical Nucleation Theory, the induction time is dependent on supersaturation and temperature ${ }^{5}$ :

$$
\ln t_{i n d}=-\ln J V=-\ln A V+\frac{16 \pi \sigma^{3} v^{2}}{3 R^{3} T^{3}(\ln S)^{2}}
$$

where $\sigma$ is the solid-liquid interfacial energy, $v$ is the molecular volume of the crystalline phase and $R$ is the gas constant. $T$ and $S$ are the temperature and the supersaturation ratio of the solution, respectively. If the pre-exponential factor, $A$, is assumed to be constant in certain range of temperature and supersaturation ${ }^{2,5}$, by plotting $\ln t_{\text {ind }}$ versus $T^{-3}(\ln S)^{-2}$, the interfacial energy $\sigma$ is determined from the slope, $B=\frac{16 \pi \sigma^{3} v^{2}}{3 R^{3}}$. Accordingly, the nucleation work and nucleus size can be extrapolated (supporting information).

By regrouping Eqn. 1 to a supersaturation dependent function $f(S)=R^{3} \cdot T^{3}(\ln S)^{2}$ and a time dependent function $f(t)=\ln \left(A V t_{\text {ind }}\right)$ in the left side of Eqn. 2, the right side of equation, 
$16 \pi \sigma^{3} \mathrm{v}^{2}$, is equal to $N$, which is the critical nucleation potential. $\mathrm{N}$ is a constant parameter for one system ${ }^{31}$ with unit of $(\mathrm{kJ} / \mathrm{mol})^{3}$.

$$
f(S) \cdot f(t)=3 R^{3} T^{3}(\ln S)^{2} \cdot \ln \left(A V t_{\text {ind }}\right)=16 \pi \sigma^{3} v^{2}=N
$$

It is noted that $t_{\text {ind }}$, in the experiment in Eqn. 1 represent the experimental results, usually used to determine the interfacial energy and nucleation work. In Eqn. 2, the induction time, $t_{\text {ind }}$, is an dependent parameter of $f(t)$, which can be estimated from different levels of supersaturation in one system with same $\mathrm{N}$, if the term $A V$ is known, i.e $f(t)$ is determined by $f(S)$ by Eqn. 2 .

The curve in Figure 2 (a) shows the equal value of critical nucleation potential $N$ for a system under each different supersaturation level, i.e. $f(S)$. The area of big green rectangle $N_{\text {iso }}$ is equal to $f(S) \cdot f(t)$. Therefore, during each time interval $\Delta t$ the area of each small green rectangle, for example $\Delta N_{i s o}[a], \Delta N_{i s o}[b]$ or $\Delta N_{i s o}[c]$, is constant, i.e. the accumulated nucleation potential, $\Delta N_{i s o}[n]$, during each short period is constant:

$$
\Delta N_{i s o}=\frac{\Delta t}{t_{n}} N=A V \Delta t \cdot \exp \left(-\frac{N}{3 R^{3} T^{3}(\ln S)^{2}}\right) N
$$

where $\exp \left(-\frac{N}{R^{3} T^{3}(\ln S)^{2}}\right)$ is constant, due to the constant temperature and supersaturation in the isothermal experiment.
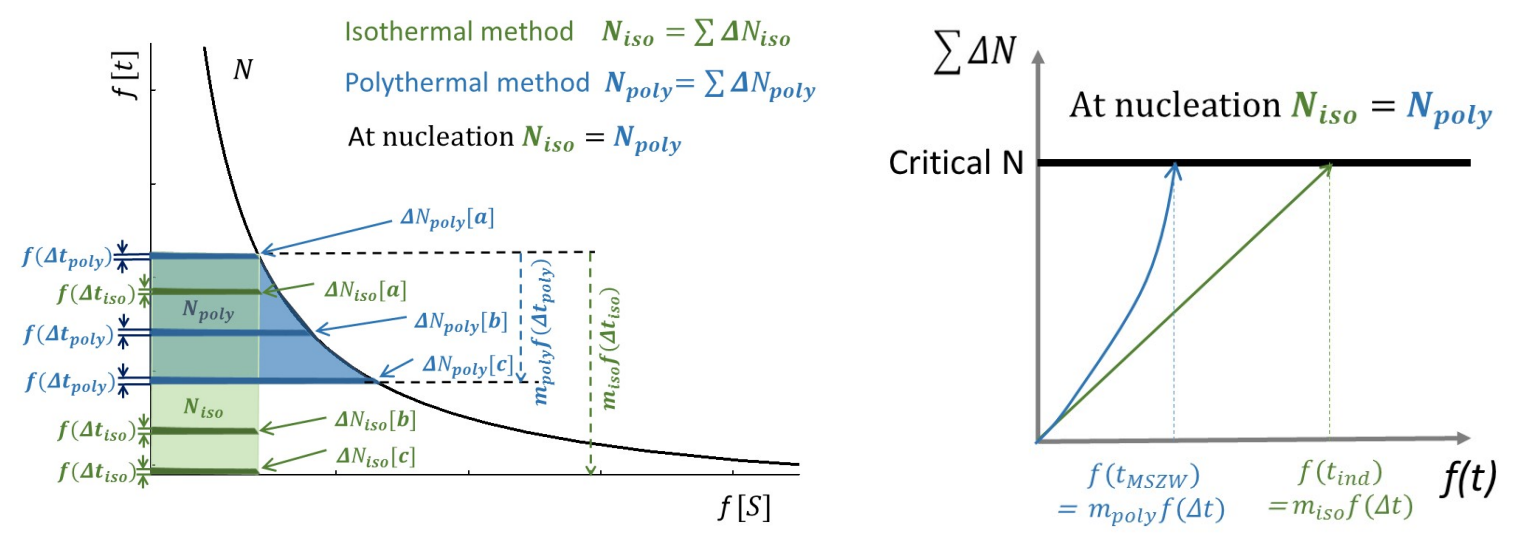
Figure 2: (a) Interpretation of the isothermal experiment (green) and the polythermal experiment (blue) by classical nucleation theory with Eqn. 2 and Eqn. 3. (b) Accumulation of nucleation potential in the isothermal experiments (green linear line) and the polythermal experiments (blue curve), corresponding to Eqn. 4 and Eqn. 5, respectively.

In order for a system to build up nucleation potential, it needs time and supersaturation. The area of the big green rectangle, $N_{i s o}$, in Figure 2 (a) (accumulated by small green rectangle, $\Delta N_{i s o}[n]$, from top to bottom) represents the integration of nucleation potential $\Delta N_{\text {iso }}$ in an isothermal experiment at a constant temperature and a constant supersaturation level. The integral over time $\mathrm{t}$ from the time constant supersaturation is generated $(\mathrm{t}=0)$ to time $t_{m}$ becomes:

$$
\int_{0}^{m_{i s o} \Delta t} \Delta N d t=\sum_{n=1}^{m} \Delta N=m_{i s o} \cdot A V \Delta t \cdot \exp \left(-\frac{N}{3 R^{3} T^{3}(\ln S)^{2}}\right) N
$$

Therefore, the accumulation of nucleation potential, $\int_{0}^{m_{i s o} \Delta t} \Delta N d t$, is a linear line in Figure 2 (b).

The blue trapezium, $N_{\text {poly }}$, in Figure 2 (a) presents the critical nucleation potential in a polythermal experiment at decreasing temperature and increasing supersaturation level. In this polythermal experiment, cumulative nucleation potential, $\Delta N_{\text {poly }}[n]$, during each $f(\Delta t)$ increases, i.e. $\Delta N_{\text {poly }}[a]<\Delta N_{\text {poly }}[b]<\Delta N_{\text {poly }}[c]$, which can be also calculated by Eqn. 3 , where $t_{n}$ decreases with increase in supersaturation.

In this work solubility equation with form of $\ln x=A_{S} T^{-1}+B_{S}+C_{S} T$ is used as in previous investigation $^{31,46}$, and other solubility equations are also applicable to this method. In a polythermal experiment linear cooling rate of $z_{c}$ is employed, and when the solution cools down 
to temperature $T_{0}$ ( $T_{0}$ is saturated temperature), time is recorded as $t=0$. The accumulated nucleation potential till time $t_{m}$ (equal to $m \Delta \mathrm{t}$ ), becomes:

$$
\int_{0}^{m_{\text {poly }} \Delta t} \Delta N d t \approx \sum_{n=1}^{m} \Delta N=\sum_{n=1}^{m} A V \Delta t \cdot \exp \left(-\frac{N}{3 R^{3} T_{\text {poly }}{ }^{3}\left(\ln S_{\text {poly }}\right)^{2}}\right) N
$$

where $T_{\text {poly }}=T_{0}-z_{c} n \Delta t$, and $\ln S_{\text {poly }}=A_{s} T_{0}^{-1}-A_{s}\left(T_{0}-z_{c} n \Delta t\right)^{-1}+C_{s} T_{0}-C_{s}\left(T_{0}-\right.$ $\left.z_{c} n \Delta t\right)$. Therefore, the accumulation of nucleation potential is an up-bended curve in Figure 2 (b), showing with longer time in a polythermal experiment, the speed of accumulating nucleation potential becomes faster.

Nucleation happens at the time of $\mathrm{m} \Delta \mathrm{t}$ when the accumulated nucleation potential is equal to or just bigger than the value of the critical nucleation potential, $N$, in both isothermal and polythermal method. It is noticed that the Eqn. 5 is simplified to the Eqn. 4, if $\mathrm{z}_{\mathrm{c}} \mathrm{n} \Delta \mathrm{t}$ is a constant. As shown in Figure 2 (b), no matter which methods applied, when the accumulation nucleation potential reaches critical value, nucleation occurs.

\section{Experimental work}

\section{Materials}

L-Ascorbic acid (CAS reg. no. 50-81-7, mass purity $>99.0 \%$ ), was purchased from Sigma-Aldrich, and used without further purification. Double distilled water was used.

\section{Nucleation experiments}

$100 \mathrm{ml}$ solution of L-ascorbic acid in pure water was prepared in a sealed $300 \mathrm{ml}$ glass bottle with concentration of $0.4468 \mathrm{~g} / \mathrm{g}$ water. The bottle was then submerged in a water bath kept at a 
constant temperature of $323.15 \mathrm{~K}$ which was about $15 \mathrm{~K}$ above the saturation temperature of 307.98 K. The solution was stirred for several hours using a magnetic stir bar during dissolution to make sure all solid material had been dissolved. The solution was transferred into glass vials (11.5 mm diameter and $1.8 \mathrm{~mL}$ volume) by syringe attached with a $0.2 \mu \mathrm{m}$ PTFE membrane filter. A PTFE-coated magnetic stir bar of size $7 \times 2 \mathrm{~mm}$ was placed in each of the glass vial, and then the vials were sealed by Parafilm outside the cover to prevent evaporation. The vials with solutions were set in Crystal 16 (Avantium Amsterdam). Agitation of $1000 \mathrm{rpm}$ was provided and the turbidity meter was used to determine the transparency of the solution. The solutions were initially clear and the nucleation was observed at the first decrease in the transparency.

Table 1 Experimental conditions with isothermal and polythermal methods.

\begin{tabular}{lll|lll}
\hline & Cooing rate & $\begin{array}{l}\text { No. of MSZW } \\
\text { measurements }\end{array}$ & & $\begin{array}{l}\text { Constant } \\
\text { temperature }\end{array}$ & $\begin{array}{l}\text { No. of induction } \\
\text { time measurements }\end{array}$ \\
\hline Exp 1-1 & $18.0 \mathrm{~K} /$ hour & 32 & Exp 2-1 & $273.15 \mathrm{~K}$ & 24 \\
Exp 1-2 & $18.0 \mathrm{~K} /$ hour & 32 & Exp 2-2 & $273.65 \mathrm{~K}$ & 24 \\
Exp 1-3 & $18.0 \mathrm{~K} /$ hour & 32 & Exp 2-3 & $275.05 \mathrm{~K}$ & 24 \\
Exp 1-4 & $9.0 \mathrm{~K} /$ hour & 32 & Exp 2-4 & $275.35 \mathrm{~K}$ & 24 \\
Exp 1-5 & $6.0 \mathrm{~K} /$ hour & 32 & Exp 2-5 & $277.45 \mathrm{~K}$ & 24 \\
Exp 1-6 & $3.0 \mathrm{~K} /$ hour & 32 & & & \\
\hline
\end{tabular}

Saturated temperature of the solution is $307.98 \mathrm{~K}$.

Totally 192 MSZWs and 120 induction times were determined (Table 1). In MSZW experiment, the linear temperature profile was controlled by the program from $323.15 \mathrm{~K}$ until all the solution nucleated, and then the vials was heated up to $323.15 \mathrm{~K}$ and kept for $30 \mathrm{~min}$. The experiments were repeated with different temperature profiles random chosen, and in sum at $3.0 \mathrm{~K} /$ hour, 6.0 $\mathrm{K} /$ hour and $9.0 \mathrm{~K} /$ hour the experiments were repeated 4 times (8 vials one group and $32 \mathrm{MSZWs}$ for each cooling rate), respectively, and repeated 12 times at $18.0 \mathrm{~K} /$ hour (96 MSZWs). In induction time experiment, the temperature of the solution was quickly cooled down to 5 constant 
temperatures from 273.15 to $277.45 \mathrm{~K}$ ( 8 vials one group and 24 induction times for each constant temperature), and the 120 induction times were determined from the solution reached constant temperature until the nucleation occurred. The median values are used to analyse the MSZWs and induction times to minimize the influence of a few very big and small results ${ }^{25}$.

\section{Results and discussions}

\section{Experimental metastable zone widths}

The wide distributions of MSZWs in Figure 3 and Figure 4 all show the stochastic nature of the nucleation. The MSZWs distributions in parallel experiments (Exp. 1-1, 1-2 and 1-3) are in good consistence with each other shown in Figure 3, indicating the reliable nucleation behaviours in this work. This consistence suggests that the median nucleation time determined from 20-30 nucleation times is as reliable as that determined from much more nucleation times.

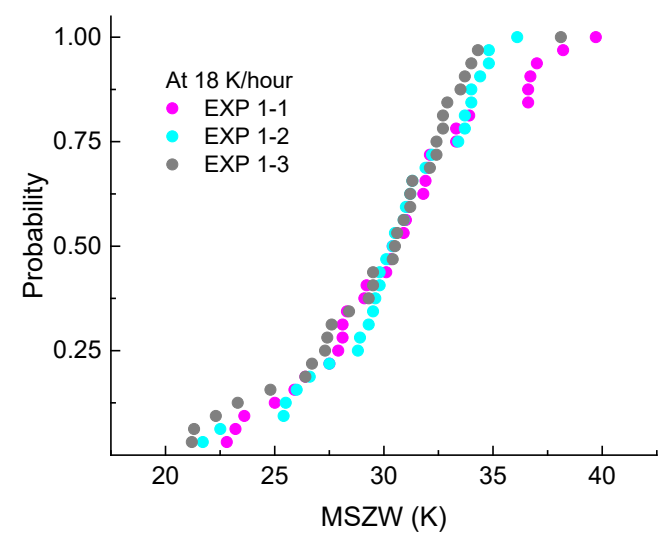

Figure 3 Cumulative distributions of the MSZWs of ascorbic acid in water at $18.0 \mathrm{~K} / \mathrm{hour}$. Three colour dots: Exp. 1-1 (pink), Exp. 1-2 (cyan) and Exp. 1-3 (grey). 


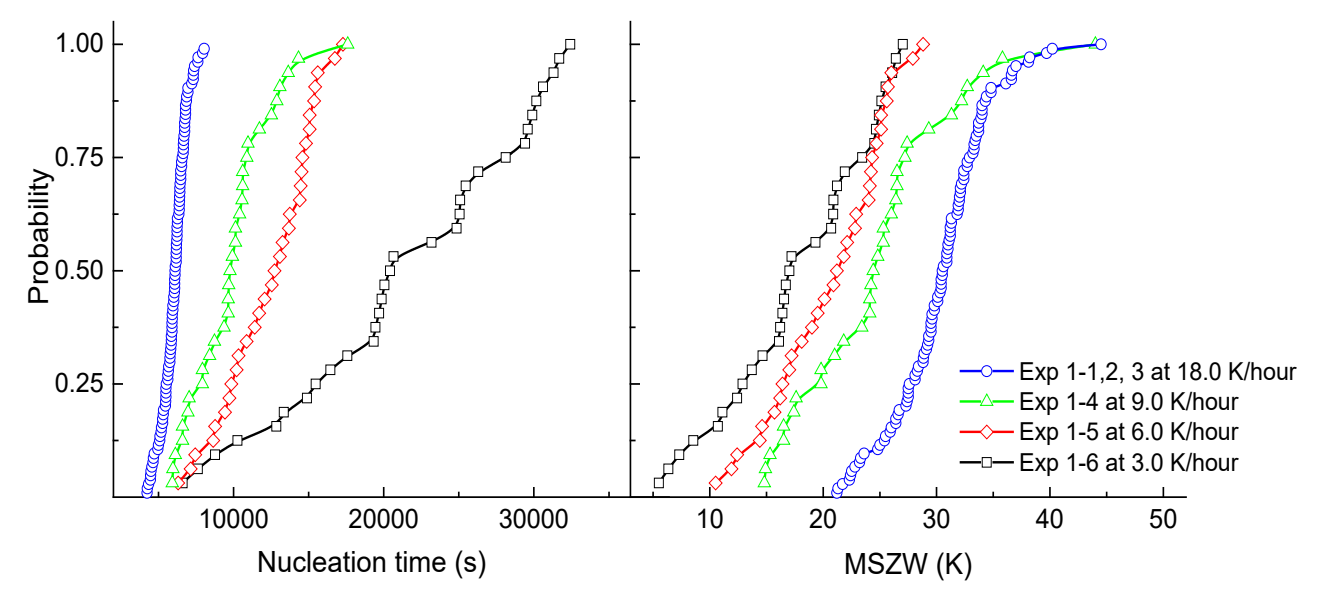

Figure 4: MSZW measurement results of ascorbic acid in water. Left figure: Cumulative distributions of the nucleation times at $18.0 \mathrm{~K} /$ hour (Exp. 1-1,2,3: 96 blue circle), $9.0 \mathrm{~K} /$ hour (Exp. 1-4: 32 green triangle), $6.0 \mathrm{~K} /$ hour (Exp. 1-5: 32 red diamond), 3.0 K/hour (Exp. 1-6: 32 black square). Right figure: Cumulative distributions of the MSZWs of the same experiments. The labels correspond to both figures.

Figure 4 shows 192 nucleation times and MSZWs at four cooling rates from $3.0 \mathrm{~K} /$ hour to 18.0 $\mathrm{K} /$ hour. At the cooling rate $3.0 \mathrm{~K} /$ hour, the nucleation times vary from 6612 to $33372 \mathrm{~s}$, corresponding to a variation in MSZW from 5.51 to $27.81{ }^{\circ} \mathrm{C}$. The variations in the nucleation times and MSZWs are thus substantial. The median nucleation time, nucleation time at $\mathrm{P}(\mathrm{t})=0.5$, increases with decreasing cooling rate that $18.0<9.0<6.0<3.0 \mathrm{~K} /$ hour. In the order from 3.0 to 18.0 K/hour, the average, lowest and largest MSZW increase, respectively. Correspondingly, the maximum driving force during the cooling process (driving force at nucleation) increases with increase of the cooling rates (Table 2). 
Table 2: Results of the experimental and extrapolated MSZWs with respective nucleation parameters of ascorbic acid in water

\begin{tabular}{rcccc|ccc}
\hline $\begin{array}{c}Z_{c} \\
(\mathrm{~K} / \text { hour })\end{array}$ & $\begin{array}{c}T_{0} \\
(\mathrm{~K})\end{array}$ & $\begin{array}{c}M S Z W_{\text {exp }} \\
(\mathrm{K})\end{array}$ & $\begin{array}{c}t_{M S Z W} \\
(\mathrm{~s})\end{array}$ & $\begin{array}{c}R T \ln S_{\max } \\
(\mathrm{kJ} / \mathrm{mol})\end{array}$ & $\begin{array}{c}N^{\frac{1}{3}} \\
(\mathrm{~kJ} / \mathrm{mol})\end{array}$ & $\begin{array}{c}A V \\
(/ \mathrm{s})\end{array}$ & $\begin{array}{c}M S Z W_{\text {ind }} \\
(\mathrm{K})\end{array}$ \\
\hline 18.0 & 307.98 & $30.51(3.96)$ & 6102 & 1.96 & 4.47 & 0.029 & 31.53 \\
9.0 & & $24.61(6.07)$ & 9844 & 1.61 & & & 28.95 \\
6.0 & & $21.51(4.80)$ & 12906 & 1.43 & & & 27.67 \\
3.0 & & $17.11(6.29)$ & 20652 & 1.15 & & & 25.76 \\
\hline
\end{tabular}

$M S Z W_{\text {exp }}$ : median experimental MSZWs with standard deviation in bracket, $t_{M S Z W}$ : median nucleation times in MSZW experiment, $R T \ln S_{\text {max }}$ : driving force at nucleation, $M S Z W_{\text {ind }}$ : MSZW extrapolated from induction time results by Eqn. 5 .

The ratios between the longest nucleation time and the onset of the nucleation time are 1.9, 2.5, 2.7 and 5.0 at the cooling rate of $18.0,9.0,6.0$ and $3.0 \mathrm{~K} /$ hour, respectively. The distribution of nucleation time widens with decreasing cooling rate. The width of the MSZW distribution is less significantly affected by the cooling rate. The median MSZWs is less than two times difference among experiments with these cooling rates, however, the difference among the median nucleation time in these experiments is more than three times, shown in Table 2.

\section{Experimental induction times and nucleation parameters}

Figure 5 shows the distributions of the induction time, at driving forces from 2.0 to $2.2 \mathrm{~kJ} / \mathrm{mol}$, the distributions of induction time at four higher driving forces are nearly parallel to each, and the longest induction time is about 3 times longer than the shortest induction time in each case. However, at the lowest driving force, the distribution of induction time is much broader than other four distributions, and the longest induction time is about 4 times longer than the shortest induction time. 


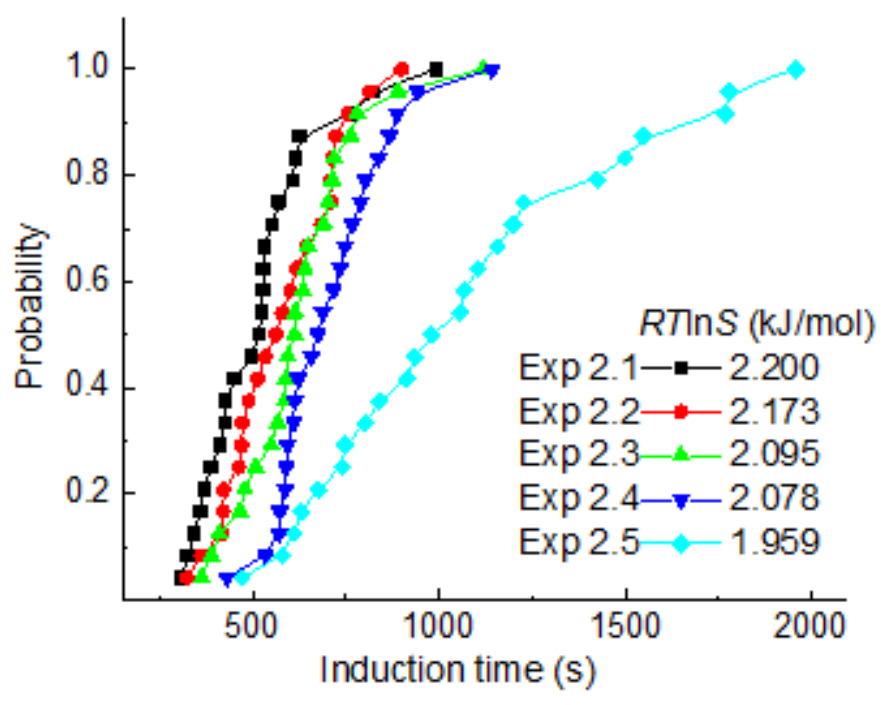

Figure 5 Accumulated distributions of induction time of ascorbic acid in water for Exp. 2-1 to Exp 2-5 from left to right (24 data for each condition) at five constant temperatures from 273.15 to $277.45 \mathrm{~K}$

Table 3 Induction time experimental results and nucleation parameters determined of ascorbic acid in water

\begin{tabular}{ccccccccc}
\hline $\begin{array}{c}C^{*} \\
(\mathrm{~g} / \mathrm{g} \text { solvent })\end{array}$ & $\begin{array}{c}R T \ln S \\
(\mathrm{~kJ} / \mathrm{mol})\end{array}$ & $\begin{array}{c}t_{\text {ind }} \\
(\mathrm{s})\end{array}$ & $\begin{array}{c}\sigma \\
\left(\mathrm{mJ} / \mathrm{m}^{2}\right)\end{array}$ & $\begin{array}{c}A V \\
(/ \mathrm{s})\end{array}$ & $\begin{array}{c}\Delta G_{c} \\
(\mathrm{~kJ} / \mathrm{mol})\end{array}$ & $\begin{array}{c}r_{c} \\
(\mathrm{~nm})\end{array}$ & $n_{c}$ \\
\hline 0.165 & 0.447 & 2.200 & $519(161)$ & 6.482 & 0.029 & 4.756 & 0.614 & 6.0 \\
0.167 & 2.173 & $569(147)$ & & & 4.878 & 0.621 & 6.2 \\
0.174 & 2.095 & $612(162)$ & & & 5.247 & 0.645 & 6.9 \\
0.176 & 2.089 & $681(152)$ & & & 5.275 & 0.650 & 7.1 \\
0.186 & 1.959 & $1018(404)$ & & & 5.998 & 0.689 & 8.4 \\
\hline
\end{tabular}

$t_{\text {ind }}$ : median induction time with standard deviation in bracket. $C^{*}$ : solubility of solution at each constant temperature, $C$ is concentration of the solution. $A$ : pre-exponential factor in solution with volume $V . r_{c}$ : critical radium of nucleus. $n_{c}$ : critical number of molecules in nucleus. $C, \sigma$ and $A V$ are same for all five conditions.

According to the Eqn. 1, from the slope and the intercept of the linear line (supporting information), the interfacial energy and the pre-exponential factor can be determined and results are given in Table 3. The Gibbs energy barriers to nucleation are about 5 to $6 \mathrm{~kJ} / \mathrm{mol}$, the sizes of the critical nucleus are about $0.6-0.7 \mathrm{~nm}$ and the critical numbers of nucleus are about 6 to 8 . The interfacial 
energy of ascorbic acid in water is $6.482 \mathrm{~mJ} / \mathrm{m}^{2}$, which is in the same order as values of several other organic compounds ${ }^{47-49}$.

\section{Extrapolated metastable zone widths from induction time experiments}

The critical nucleation potential of ascorbic acid in water is $89.55(\mathrm{~kJ} / \mathrm{mol})^{3}$, and AV is $0.029 \mathrm{~s}^{-1}$ (shown in Table 2), calculated by the Eqn. 2. At constant cooling rate $18.0 \mathrm{~K} /$ hour $(0.005 \mathrm{~K} / \mathrm{sec})$, the temperature is equal to $307.98-0.005 n \Delta t \mathrm{~K}$ at time $n \Delta \mathrm{t}$ with unit of second. If the time step, $\Delta t$, is 1 second, combining the solubility equation, $\ln x=21.123 T^{-1}-11.845+0.028 T$, with Eqn. 5, the accumulated nucleation potential of every time step (one second) during the cooling process can be calculated (shown in supporting information).

The nucleation occurs at $\sum_{n=1}^{m} \Delta N \geq 89.55(\mathrm{~kJ} / \mathrm{mol})^{3}$ with the minimum value of $m=6306$, and then the MSZW can be calculated as $31.53 \mathrm{~K}$. The same method is used to extrapolate MSZWs at cooling rates at 3.0,6.0 and $9.0 \mathrm{~K} /$ hour, and the minimum value of $m$ is 30912,16602 and 11580 , respectively. The extrapolated MSZW results are shown in the last column of Table 2. By similar format equations starting from Eqn. 5, the MSZW of same results would also be estimated by the integral equation (infinite small step) suggested by Shiau ${ }^{30,33-34}$. 


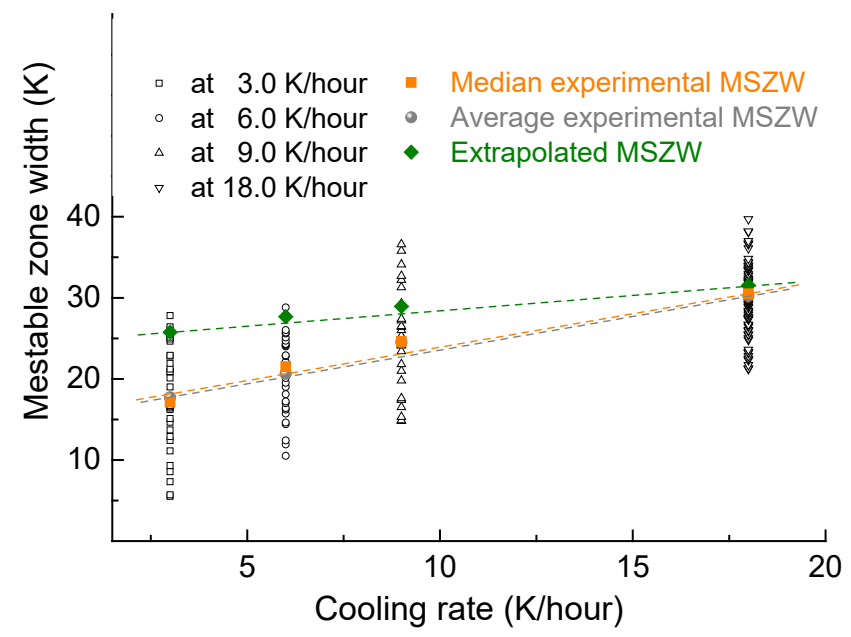

Figure 6 Experimental results of L-ascorbic acid MSZW (black open dots) in water with median values (brown round solid dots), average values (green round solid dots), and MSZWs extrapolated by Eqn. 5 from induction time experiments (blue diamond solid dots) at cooling rate 3.0, 6.0, 9.0 and $18.0 \mathrm{~K} /$ hour (from left to right), respectively. Dashed lines are guiding lines of respective data.

In this work, the median values of induction times, nucleation times and MSZWs are very close to the respective average values. Figure 6 shows the extrapolated MSZW at $18.0 \mathrm{~K} /$ hour are in good consistence with the experimental value, about only $1 \mathrm{~K}$ higher. All the extrapolated values are higher than the respective experimental values, and at lower cooling rates, the deviations between extrapolated values with experimental values increase from 4 to $8 \mathrm{~K}$.

Few induction times and MSZWs are both reported in the same systems. In isonicotinamide ethanol ${ }^{16}$ solution at cooling rates 6.0 to $60.0 \mathrm{~K}$ /hour, the extrapolated MSZW s ${ }^{31}$ from induction time results are 11.3 to $17.3 \mathrm{~K}$ (shown in supporting information), which are in good agreement with the experimental results from 7.7 to $17.1 \mathrm{~K}$. In paracetamol - ethanol ${ }^{50}$ at cooling rate 12.0 
to $60.0 \mathrm{~K}$ /hour, the extrapolated MSZWs with Equ. 5 from experimental induction times are 12.6 to $19.6 \mathrm{~K}$, which are in good consistence with the experimental MSZWs from 11.1 to $21.0 \mathrm{~K}$.

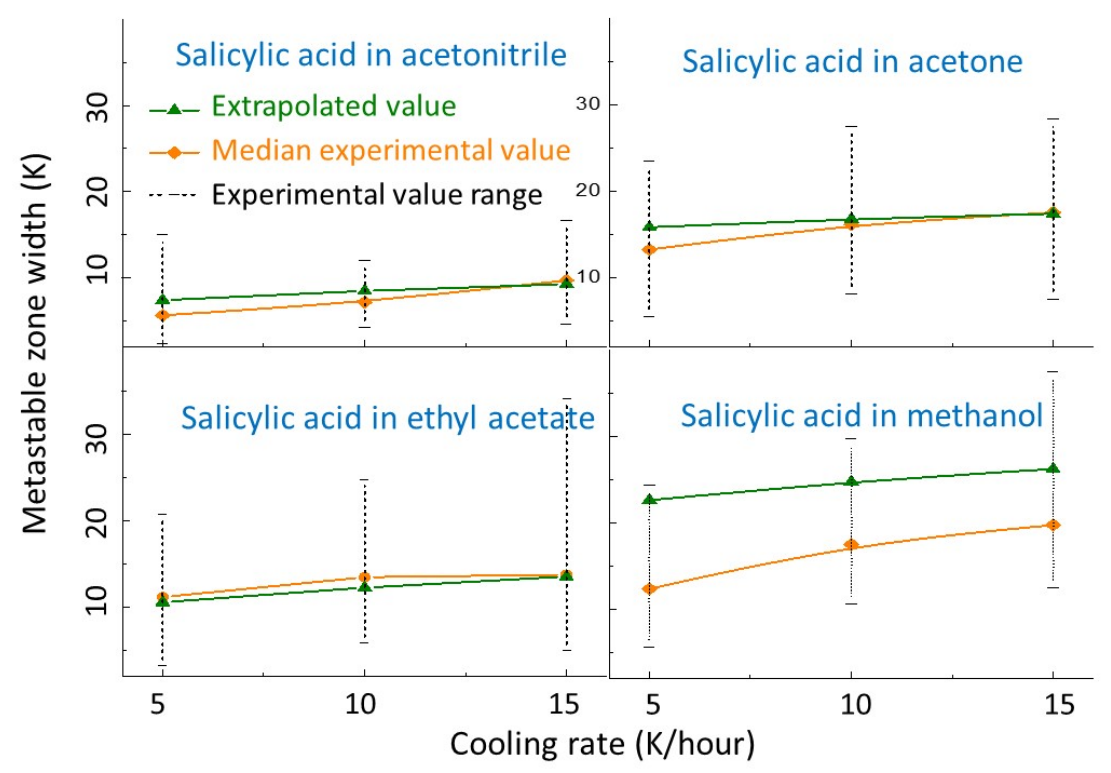

Figure 7: Experimental MSZWs ${ }^{51}$ and extrapolated values by Eqn. 5 of salicylic acid in acetonitrile, acetone, ethyl acetate and methanol from experimental induction time results.

Recently, the induction times and MSZWs of salicylic acid in acetonitrile, acetone, ethyl acetate and methanol have been reported ${ }^{51}$, shown in Figure 7. In acetonitrile, acetone and ethyl acetate, MSZWs of salicylic acid extrapolated from induction times are of very good consistence with the experimental results. In acetonitrile, experimental MSZWs are $5.6-9.7 \mathrm{~K}$ at $5-15 \mathrm{~K} /$ hour which are consistent with the estimated values $7.4-9.3 \mathrm{~K}$ from induction time results. In acetone, the experimental MSZWs are $13.2-17.5 \mathrm{~K}$ which are in consistence with the estimated MSZW values 15.8 - $17.4 \mathrm{~K}$. In ethyl acetate, the experimental MSZWs are $11.1-13.7 \mathrm{~K}$ which are also close to the estimated values $10.5-13.5 \mathrm{~K}$. In methanol, estimated MSZWs of salicylic acid have bigger variations with the experimental values of $12.3-19.7 \mathrm{~K}$, and the extrapolated values are overall about $9 \mathrm{~K}$ higher. 


\section{Estimated induction times from metastable zone width experiments}

An optimization method is applied to find the best fitting MSZW at each cooling rate to the experimental MSZW, and respective interfacial energy, pre-exponential factor and induction time at each driving force can be estimated from the optimized MSZW. By calculation of the objective function, Eqn. 6, (the difference between experimental values and extrapolated values with one or more cooling rates) for every possible combination values of $N$ and $A V$,

$$
F_{\text {opti }}=\sum_{i=z_{c}}\left(M S Z W_{\text {exp }}-M S Z W_{\text {extra }} \mid(N, A V)\right)^{2}
$$

where $M S Z W_{\text {extra }}$ is estimated from Eqn. 5. Ten thousands values of $M S Z W_{\text {extra }}$ with respective ten thousands combinations of $\mathrm{N}$ and $\mathrm{AV}$ have been calculated and compared with experimental values by a program in Matlab 2014b. The combination values of $\mathrm{N}$ and $\mathrm{AV}$, leading to the minimum $F_{\text {opti }}$, are used to estimate induction times.

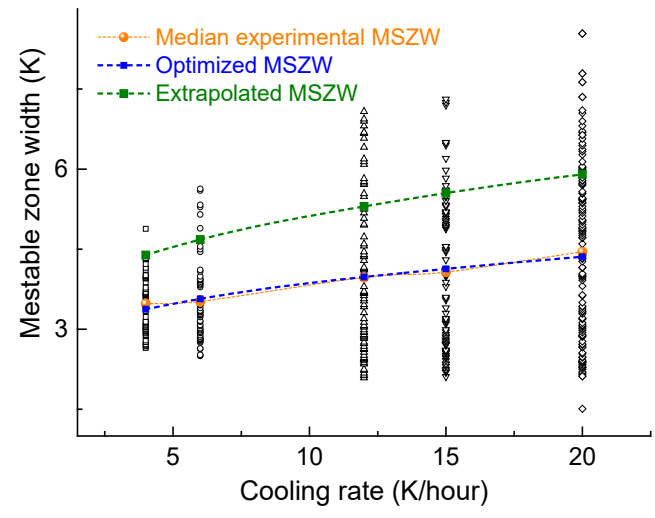

(a)

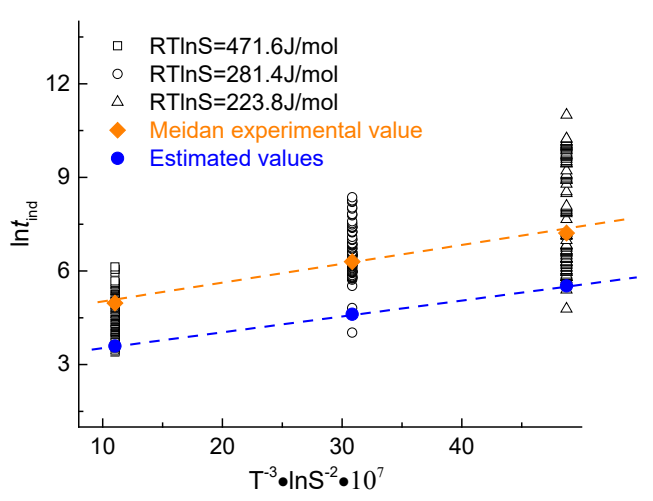

(b)

Figure 8 Experimental MSZWs (a) / induction times (b) and MSZWs (a) / induction times (b) estimated from optimization of MSZWs of butyl paraben in ethanol. 
As an example of butyl paraben in ethanol, the experimental MSZWs at 4.0, 6.0, 12.0, 15.0 and $20.0 \mathrm{~K} /$ hour are shown in Figure 8 (a). By testing the values of $\mathrm{N}$ and $\mathrm{AV}$ determined by induction time experiments, $F_{\text {opti }}$ is about $8.5 K^{2}$, shown as green dots in Figure 8 (b). With different values of $\mathrm{N}$ and $\mathrm{AV}$, the estimated MSZWs calculated by Eqn. 5 move along each vertical line (for each cooling rate), accordingly leading to different values of $F_{\text {opti }}$. The blue dots on dashed line in Figure 8 (a) are almost overlapping to the experimental values, which has the minimum value of $F_{\text {opti }}, 0.02 \mathrm{~K}^{2}$, among all the combinations of $\mathrm{N}$ and $\mathrm{AV}$ tested. In this case, the optimized $\mathrm{N}$ and $\mathrm{AV}$ are $1.09 \mathrm{~kJ}^{3} \mathrm{~mol}^{-3}$ and $0.050 \mathrm{~s}^{-1}$, respsctively. From $\mathrm{N}$ and AV, we can estimate induction time at the experimental supersaturation levels, shown as the blue dots on blue dashed line in Figure 8 (b). The interfacial energy determined from the optimized MSZWs are 1.073 $\mathrm{mJ} / \mathrm{m}^{2}$ which is in good agreement with the value $1.134 \mathrm{~mJ} / \mathrm{m}^{2}$ determined from the experimental induction time results.

Table 4 Estimated interfacial energies and pre-exponential factors from optimization Eqn. 6 of butyl paraben in ethanol, salicylic acid in ethyl acetate and paracetamol in ethanol.

\begin{tabular}{llcccc}
\hline $\begin{array}{l}\text { Optimization of } N \\
\text { and } A V\end{array}$ & & $\begin{array}{l}F_{\text {opti }} \\
\left(\mathrm{K}^{2}\right)\end{array}$ & $\begin{array}{c}\mathrm{N} \\
\left(\mathrm{kJ}^{3} \mathrm{~mol}^{-3}\right)\end{array}$ & $\begin{array}{c}A V \\
\left(\mathrm{~S}^{-1}\right)\end{array}$ & $\begin{array}{c}\sigma \\
\left(\mathrm{mJ} \mathrm{mol}^{-1}\right)\end{array}$ \\
\hline $\begin{array}{l}\text { Butyl paraben } \\
\text { in ethanol }\end{array}$ & Experimental & 8.47 & 1.09 & 0.014 & 1.134 \\
\hline Salicylic acid & Estimated & 0.02 & 0.93 & 0.050 & 1.073 \\
in ethyl acetate & Extimated & 1.85 & 1.67 & 0.0030 & 1.836 \\
\hline Paracetamol & Experimental & 4.64 & 2.50 & 0.0050 & 2.099 \\
in ethanol & Estimated & 0.80 & 3.96 & 0.0042 & 2.090 \\
\hline
\end{tabular}

With Eqn. 6, estimated and experimental MSZWs of butyl paraben in ethanol at only one cooling rate are also compared, the $F_{\text {opti }}$ is very close to 0 , i.e. optimized MSZW can be almost same as the experimental values at this cooling rate. From each optimized MSZW (five optimized MSZWs at five single cooling rate), the interfacial energy is estimated in the range of $1.0-1.1 \mathrm{~mJ} / \mathrm{m}^{2}$ (in 
supporting information), which are of good consistence with the experimental value. Accordingly, the estimated induction times at different supersaturation levels are consistent with the experimental values.

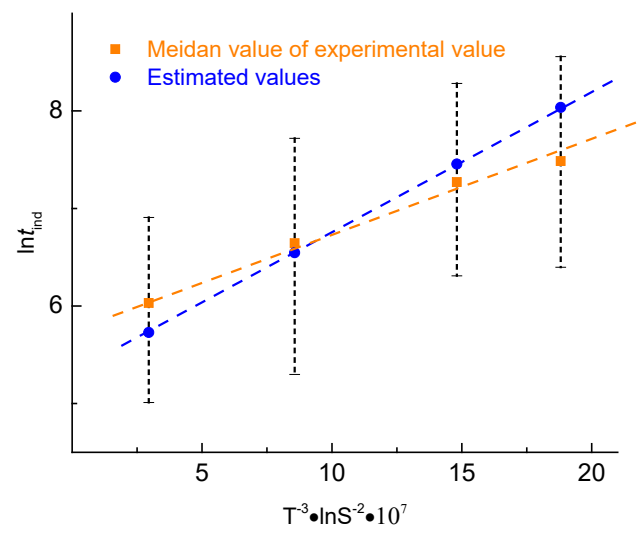

(a)

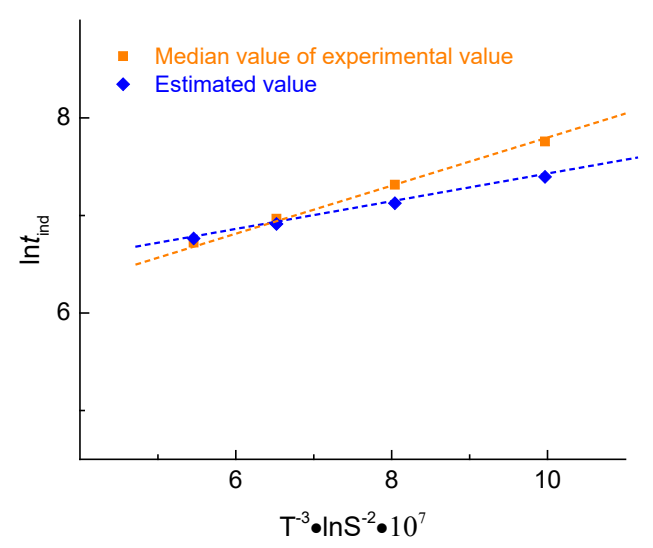

(b)

Figure 9 Estimated induction times of (a) salicylic acid in ethyl acetate and (b) paracetamol in ethanol from optimized MSZWs.

From the best fitting MSZWs of salicylic acid in ethyl acetate at cooling rates at $5-15 \mathrm{~K} /$ hour and MSZWs of paracetamol in ethanol at cooling rates $12-60 \mathrm{~K} / \mathrm{hour}, \mathrm{N}$ and $\mathrm{AV}$ are estimated to be $2.50 \mathrm{~kJ}^{3} / \mathrm{mol}^{3}$ and $2.41 \mathrm{~kJ}^{3} / \mathrm{mol}^{3}$ with AV as $0.050 \mathrm{~s}^{-1}$ and $0.0025 \mathrm{~s}^{-1}$, respectively. Very low $F_{\text {opti }}$ values indicate the optimized MSZWs are very close to the experimental values. The estimated induction times are shown as blue dots on blue dashed line in Figure 9. In systems of salicylic acid in ethyl acetate and paracetamol in ethanol, the interfacial energies estimated from best fitting MSZWs, $2.099 \mathrm{~mJ} / \mathrm{mol}$ and $1.772 \mathrm{~mJ} / \mathrm{mol}$, are consistent with the experimental values $1.836 \mathrm{~mJ} / \mathrm{mol}$ and $2.090 \mathrm{~mJ} / \mathrm{mol}$, respectivly. In addition, if MSZW at each cooling rate is fitted by Eqn. 6, the estimated interfacial energy and pre-exponential factor at each cooling rate are also consistent with the experimental values, respectively. 
However, in the system of L-ascorbic acid in water, probably due to wide MSZWs, there are big variations (about $30 \%$ ) between estimated MSZWs with experimental MSZWs at lower cooling rates (in Figure 6), and, correspondingly, there are big variations (about $50 \%$ ) between experimental induction times with estimated values by fitting MSZWs at all cooling rates.

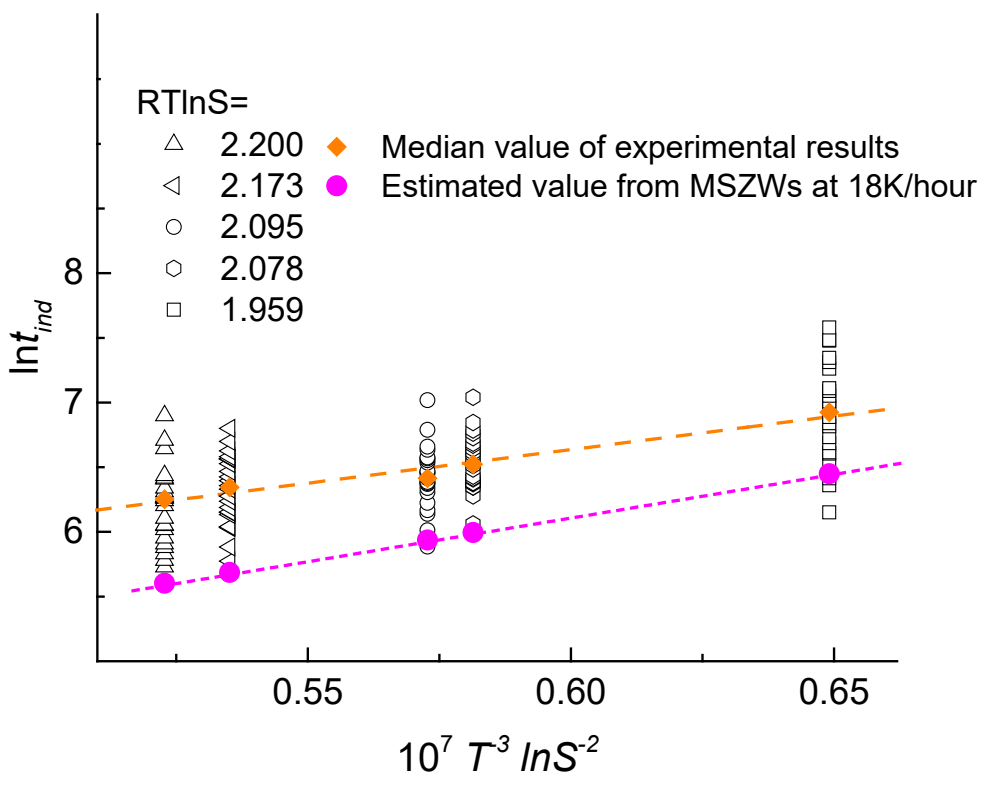

Figure 10 Experimental induction times and estimated induction times from MSZW at 18.0 $\mathrm{K} /$ hour and estimated induction times with different A values by fitting MSZW at each corresponding cooling rate.

If we estimate the induction time from MSZW at single cooling rate, applying the Eqn. 6 with each cooling rate, the interfacial energy estimated from cooling rate at $18.0 \mathrm{~K} /$ hour are closest to the experimental values (Table 5) than those at other cooling rates. The estimated interfacial energy is $7.055 \mathrm{~mJ} / \mathrm{mol}$, which is close to experimental value $6.482 \mathrm{~mJ} / \mathrm{mol}$ with only about $3 \%$ variation. Correspondingly, estimated induction time from fitting MSZW only at $18.0 \mathrm{~K} /$ hour is the closest to the experimental induction time value, shown in Figure 10, than estimated induction time from fitting MSZW at other individual cooling rate. This may be because the wide MSZWs or big gap 
between nucleation temperature in polythermal and in isothermal experiments invalidate the assumption that pre-exponential factor, A, is constant, i.e. independent on temperature. If we fit each MSZW with constant N (determined from induction time experiments) at each cooling rate, the values of A systematically decrease with increase in cooling rates, i.e. decrease in the nucleation temperature, shown in Table 5, which show a strong influence of the temperature on the pre-exponential factors.

Table 5 Estimated interfacial energies or pre-exponential factors by optimizing MSZWs of ascorbic acid in water with Eqn. 6 at each cooling rate

\begin{tabular}{lc|cccc}
\hline Ascorbic acid in water & $\begin{array}{c}\text { Optimization } \\
\text { conditions }\end{array}$ & $\begin{array}{c}F_{\text {opti }} \\
\left(\mathrm{K}^{2}\right)\end{array}$ & $\begin{array}{c}\mathrm{N} \\
\left(\mathrm{kJ}^{3} \mathrm{~mol}^{-3}\right)\end{array}$ & $\begin{array}{c}\mathrm{AV} \\
\left(\mathrm{s}^{-1}\right)\end{array}$ & $\begin{array}{c}\sigma \\
\left(\mathrm{mJ} \mathrm{mol}^{-1}\right)\end{array}$ \\
\hline Experimental & & 132.51 & 89.57 & 0.029 & 6.482 \\
\hline Optimization of N and AV & at $18.0 \mathrm{~K} /$ hour & 0.00 & 115.51 & 0.122 & 7.055 \\
\hline Optimizations of each AV & at 3.0K/hour & 0.00 & 89.57 & 5.366 & \\
value at corresponding & at $6.0 \mathrm{~K} /$ hour & 0.00 & & 0.878 & \\
cooling rate with constant N & at 9.0K/hour & 0.00 & & 0.150 & \\
value & at18.0K/hour & 0.00 & & 0.041 & \\
\hline
\end{tabular}

\section{Discussion}

The smaller critical nucleation potential is, the narrower MSZW becomes. The critical nucleation potentials, calculated from induction time results of different systems in this work and in literatures, are in the range 1.1 to $89.6(\mathrm{~kJ} / \mathrm{mol})^{3}$, and MSZWs reported in these systems are in the range from 3.4 to $30.5 \mathrm{~K}$ at the cooling rates in the range of 3 to $60 \mathrm{~K} /$ hour. The critical nucleation potentials of the systems are in the order: ascorbic acid in water $>$ salicylic acid in methanol $>$ salicylic acid in acetone $>$ isonicotinamide in ethanol $>$ paracetamol in ethanol $\sim$ salicylic acid in ethanol > salicylic acid in ethyl acetate $>$ butyl paraben in ethanol, and with the similar trend the MSZWs follow at comparable cooling rates, shown in Figure 11. The ascorbic acid in water have much higher critical nucleation potential than other systems, and accordingly, the MSZWs are 
much wider than other systems, while the butyl paraben in ethanol has very small critical nucleation potential, and the MSZWs (very narrow) are in the bottom of Figure 11. Figure 11 shows MSZWs increase with increase in the critical potentials and with increase in the cooling rates, which indicate that the critical nucleation potentials determine the widths of metastable zone and the cooling rates (shown as dashed lines) determine the accumulative rates of nucleation potential to reach critical nucleation potential at each system.

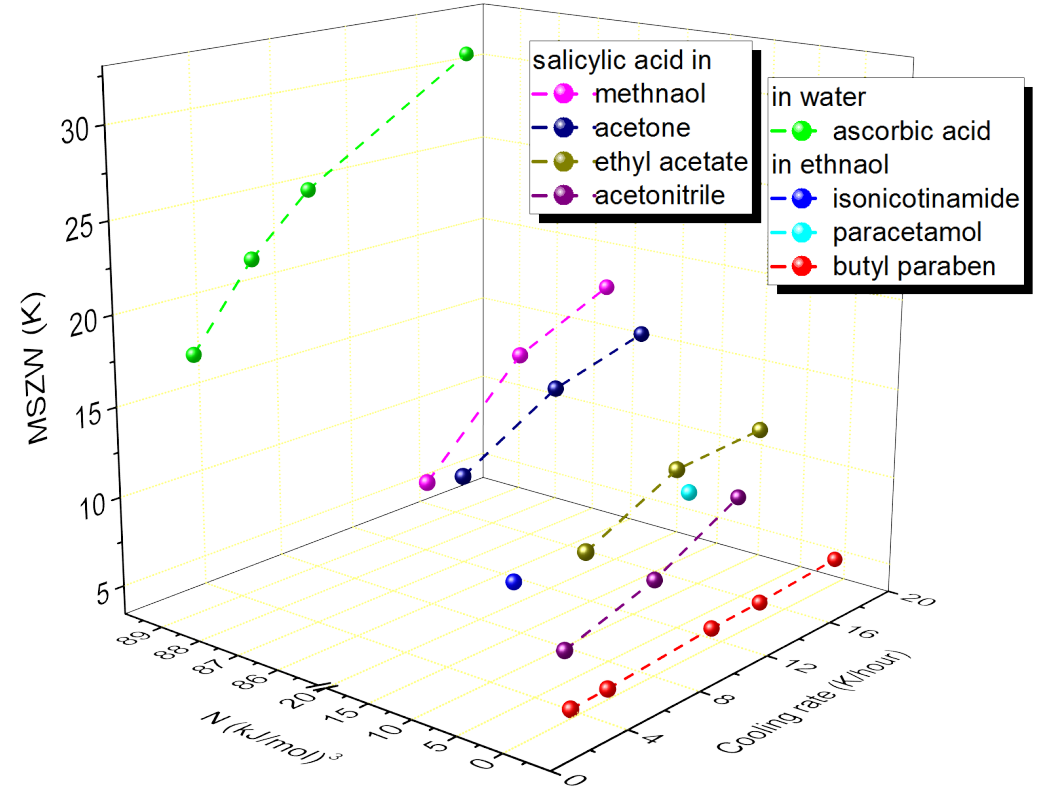

Figure 11 Relation of experimental MSZWs with critical nucleation potentials, determined from experimental induction times, at comparable range of cooling rates $(0-20 \mathrm{~K} / \mathrm{hour})$ in eight solution systems.

From the relation developed in this work, the MSZW and induction time can be estimated from each other. However, it is much more complicated to estimate the nucleation parameters from MSZWs than to estimate MSZWs from induction times, mainly because of the increasing 
accumulated nucleation potentials and other uncertainties with decreasing temperature in experiments. As assumed, the stationary nucleation (having the stationary distribution of clusters) occurs in the isothermal experiment, however, in polythermal experiment the situation of the distribution of the clusters might be continuously transforming, i.e. not stationary at each time moment. It is a reliable method that we can estimate the interfacial energies and pre-exponential factors from MSZWs in most of the systems reported. In some cases, we can estimate the interfacial energy and pre-exponential factor from only one MSZW, which values are consistent with experimental values determined from induction time experiment. Correspondingly, it shows the possibility that prediction of nucleation temperature in MSZWs or induction time from only one MSZW measurement. It is to be noticed that some of the optimizations (large number of calculation needed) takes long time to find the best fitting MSZWs by completing global optimizations and the optimization function is very sensitive to the nucleation parameters.

The influences of interfacial energies and pre-exponential factors in the MSZW experiment are very complicated to be simply clarified. Solvent shell / dissolvation ${ }^{1,4,52}$ paly important role in nucleation, and the water molecule is a very polar molecule usually forming strong solvent shells and the dissolvation is relatively difficult ${ }^{53}$. Because of the limited understanding of the dissolvation process and dissolvation energy, it is hard to fully predict the influences of dissolvation process on the relation, which is also the challenge of the classical nucleation theory.

In all the experiment reported in this work, there is no transition from homogeneous nucleation to heterogeneous nucleation in induction times analyzed by Eqn. 1. It is challenge to distinguish the heterogeneous nucleation and homogeneous nucleation in MSZW experiments. From the theory, the heterogeneous nucleation happens at lower supersaturation, for example $\mathrm{S}^{*}$. If the nucleation happens at supersaturation level lower than $\mathrm{S}^{*}$, the homogeneous nucleation transforms to 
heterogeneous nucleation ${ }^{5}$, when we keep solution at a constant supersaturation level. In this work, the max supersaturation in MSZW experiment is always higher than $S^{*}$, we ignore the heterogeneous nucleation in the estimations. We cannot deny in a certain MSZW experiment with very low cooling rate, the max supersaturation at nucleation may be lower than $\mathrm{S}^{*}$. Should we accept that the heterogeneous nucleation happens in this case? In our work, if we can estimate the critical nucleation potential in heterogeneous nucleation, which should be smaller than that in the homogeneous nucleation for one system, i.e. interfacial energy is smaller in heterogeneous nucleation. Correspondingly, the estimated MSZW from the critical nucleation potential in heterogeneous nucleation should be smaller than what we estimated in this work.

Because of the limitation of technology, we can observe the nucleation only after secondary nucleation induced by one or several big enough crystals, which grow during the growth time, $t_{g}$, after the initial nucleation ${ }^{54}$. However, uncertainty of the growth time is not investigated here to simplify the equation of the relation between MSZWs and induction times. In the MSZW experiments if solutions cool down to an equal temperature, at a lower cooling rate longer growth time spends and bigger mother crystal obtains. Accordingly, at a lower cooling rate less growth time needed to form a big enough nucleus, i.e. less temperature difference is needed to induce secondary nucleation, which may attribute a relatively narrower MSZW than expected.

In the equation of the relation, the pre-exponential factor is simplified to be constant. However, the influence of pre-exponential factor is unneglectable where the metastable zone width is wide, i.e. critical nucleation potential is high and nucleation is very difficult. The pre-exponential factors we estimated from optimization by fitting MSZWs decrease with decreasing temperature (Table 5) as expected. Since with the increase in cooling rate, the MSZW increases, the influence of 
temperature on $\mathrm{AV}$ magnifies, leading to a bigger variation of the prediction from this equation of the relation. However, it is noticed that at a faster cooling rate of ascorbic acid aqueous solution, the estimated MSZW has smaller variation with experimental values and the estimated value of AV from MSZW is closer to that determined from induction time experiments. The reason should be that the nucleation temperature in MSZW experiment at a faster cooling rate is nearer to the constant temperature (range) in the induction time experiments, which indicate weaker influence of AV on the prediction than the MSZW determined at a slow cooling rate. Shiau ${ }^{34}$ has investigated the influence of temperature on pre-exponential factor with similar principle equations. The dependency of pre-exponential factor on temperature is much more complicated. The dependency of kinetics on temperatures and the optimized cooling rates for estimating between MSZW and induction time will be further investigated.

From the equation of the relation, it is possible to predict the influence of the volume and saturation temperature, and stirring rate, which are all consistent with the literatures reported tendency of the effect of cooling rate ${ }^{36}$, volume ${ }^{14-15}$, saturation temperature ${ }^{38} 40$ and stirring rate ${ }^{41}$ as discussed in last work. In this work, we show the relation between isothermal and polythermal methods. With this relation, it is potential to predict the MSZW / nucleation temperature under more complicated temperature profiles, like cooling profiles of polynomial equations, step cooling in multistage parallel crystallizers, continuous oscillatory baffled crystallizer, as well as to potentially estimate the nucleation temperature with scaling up and between these continuous crystallizers. In addition, it is potential to estimate critical nucleation potential / interfacial energy and preexponential factor by single or several MSZWs.

\section{Conclusions}


In total 312 nucleation experiments of L-ascorbic acid aqueous solutions (saturated at $208 \mathrm{~K}$ ) were performed with isothermal or polythermal methods. For each experimental condition, dozens of experiments were repeated and accumulative distributions of induction times or nucleation times show the stochastic nature of the nucleation. 192 of these nucleated at $277-291 \mathrm{~K}$ (median) at respective cooling rate of $3.0-18.0 \mathrm{~K} /$ hour in polythermal experiments. 120 of these nucleated at constant temperature $273-277 \mathrm{~K}$, with respective median induction time from $500-1000 \mathrm{~s}$ in isothermal experiments. The relations between MSZWs and induction times, developed by the Classical Nucleation Theory, reveal nucleation happens when nucleation potential, during each short time interval, accumulates up to the critical nucleation potential, which is constant for a system. With the equation of the relation, the induction time and MSZW were estimated from each other. In most systems reported in literature, the MSZWs estimated from experimental induction times have an average $2.5 \mathrm{~K}$ difference with the experimental MSZWs, and the interfacial energies estimated from experimental MSZWs have an average $0.2 \mathrm{~mJ} / \mathrm{mol}$ difference with those determined from experimental induction times. In ascorbic acid - water system, MSZW estimated at $18.0 \mathrm{~K} /$ hour is $1 \mathrm{~K}(3 \%)$ higher than the experimental value, and the interfacial energy estimated from MSZW at $18.0 \mathrm{~K} /$ hour is $0.6 \mathrm{~mJ} / \mathrm{mol}(10 \%)$ higher than that determined by induction time results. The variations in estimations indicate the influences of the temperature on the preexponential factors, which is consistent with the optimization results of pre-exponential factor at each cooling rate in ascorbic acid aqueous system. With this equation of the relation, it is possible to predict MSZWs with complicated temperature profiles, which is useful for designs of continuous and batch crystallization processes, and it is possible to determine the interfacial energy from single or several MSZWs, helping to advance understanding of the solute-solvent interactions in nucleation processes. 


\section{Notations}

\begin{tabular}{|c|c|c|}
\hline$A$ & Pre-exponential factor & {$\left[\mathrm{m}^{-3} \cdot \mathrm{s}^{-1}\right]$} \\
\hline$A_{s}, B_{s}, C_{s}$ & Constant in solubility equation & \\
\hline$B$ & Slope in determination of interfacial energy & {$\left[\mathrm{K}^{3}\right]$} \\
\hline$b_{1}$ & Constant in empirical nucleation rate equation & {$\left[\mathrm{m}^{-3} \cdot \mathrm{s}^{-1}\right]$} \\
\hline$b_{2}$ & Constant in empirical nucleation rate equation & \\
\hline$f(S), f\left(S_{n}\right)$ & Function of supersaturation & {$\left[\mathrm{kJ}^{3} \cdot \mathrm{mol}^{-3}\right]$} \\
\hline$f(t), f\left(t_{n}\right)$ & Function of time, function of estimated induction time & \\
\hline$J$ & Nucleation rate & {$\left[\mathrm{m}^{-3} \cdot \mathrm{s}^{-1}\right]$} \\
\hline$m$ & Integer number parameter in accumulation equation & \\
\hline$M S Z W_{\text {exp }}$ & Experimental metastable zone width in & {$[\mathrm{K}]$} \\
\hline$M S Z W_{\text {ind }}$ & $\begin{array}{l}\text { Extrapolated metastable zone width from combination } \\
\text { values of } \mathrm{N} \text { and } \mathrm{AV}\end{array}$ & {$[\mathrm{K}]$} \\
\hline$M S Z W_{\text {extra }}$ & $\begin{array}{l}\text { Extrapolated metastable zone width from induction time } \\
\text { experiments }\end{array}$ & {$[\mathrm{K}]$} \\
\hline$n$ & Integer number variable from 1 to $\infty$ & \\
\hline$N$ & Critical nucleation potential & {$\left[\mathrm{kJ}^{3} \cdot \mathrm{mol}^{-3}\right]$} \\
\hline$r_{c}$ & Critical nuclei radius & {$[\mathrm{nm}]$} \\
\hline$R$ & Gas constant, 8.314 & {$\left[\mathrm{~J} \cdot \mathrm{mol}^{-1} \cdot \mathrm{K}^{-1}\right]$} \\
\hline$S, S_{n}, S_{\text {poly }}$ & Supersaturation & \\
\hline$S_{\max }$ & Supersaturation at nucleation in MSZW experiment & \\
\hline$t_{\text {ind }}$ & Induction time of nucleation & {$[\mathrm{s}]$} \\
\hline$t_{M S Z W}$ & Nucleation time in MSZW experiment & {$[\mathrm{s}]$} \\
\hline$t_{n}$ & Induction time, estimated induction time & {$[\mathrm{s}]$} \\
\hline$T$ & Temperature & {$[\mathrm{K}]$} \\
\hline$T_{0}$ & Saturated temperature & {$[\mathrm{K}]$} \\
\hline$v$ & Molecular volume of solute & {$\left[\mathrm{m}^{3}\right]$} \\
\hline$V$ & Solution volume & {$\left[\mathrm{m}^{3}\right]$} \\
\hline$x$ & Actual solute molar fraction solubility & {$\left[\mathrm{mol} \cdot \mathrm{mol}^{-1}\right.$ total $]$} \\
\hline$x^{*}$ & Equilibrium solute molar fraction solubility & {$\left[\mathrm{mol} \cdot \mathrm{mol}^{-1}\right.$ total $]$} \\
\hline$z_{c}$ & Linear cooling rate & {$\left[\mathrm{K} \cdot \mathrm{S}^{-1}\right]$} \\
\hline$\sigma$ & Interfacial energy in primary nucleation & {$\left[\mathrm{mJ} \cdot \mathrm{m}^{-2}\right]$} \\
\hline$\Delta G_{C}$ & Critical free energy of nucleus & {$\left[\mathrm{kJ} \cdot \mathrm{mol}^{-1}\right]$} \\
\hline$\Delta N, \Delta N_{n}[n]$ & Nucleation potential accumulated during $\Delta \mathrm{t}$ & {$\left[\mathrm{kJ}^{3} \cdot \mathrm{mol}^{-3}\right]$} \\
\hline$\Delta t$ & Time step, short time period & {$[\mathrm{s}]$} \\
\hline$\Delta T$ & Supercooling temperature & {$[\mathrm{K}]$} \\
\hline$\Delta \mu$ & Driving force of nucleation, RTInS & {$\left[\mathrm{kJ} \bullet \mathrm{mol}^{-1}\right]$} \\
\hline Uncertainty & $\begin{array}{l}\text { Difference between the estimated and experimental value / } \\
\text { average of the estimated and experimental value }\end{array}$ & - \\
\hline
\end{tabular}

\section{Acknowledgments}


We acknowledge the EPSRC Centre for Innovative Manufacturing in Continuous Manufacturing and Crystallization for funding, grant ref: EP/I033459/1. We thanks Joop ter Horst for discussions about the nucleation that improved the manuscript.

\section{References}

1. Davey, R. J.; Schroeder, S. L.; ter Horst, J. H., Nucleation of Organic Crystals-A Molecular Perspective. Angewandte Chemie International Edition 2013, 52 (8), 2166-2179.

2. Mullin, J. W., Crystallization. Butterworth-Heinemann: 2001.

3. Yang, H.; ter Horst, J. H., Crystal nucleation of small organic molecules. In New Perspectives on Mineral Nucleation and Growth, Springer: 2017; pp 317-337.

4. Yang, H.; Svard, M.; Zeglinski, J.; Rasmuson, Å. C., Influence of Solvent and Solid-State Structure on Nucleation of Parabens. Cryst. Growth Des. 2014, 14 (8), 3890--3902.

5. Kashchiev, D., Nucleation: basic theory with applications. Butterworth-Heinemann: 2000.

6. Nyvlt, J., Kinetics of industrial crystallization. Elsevier Science Pub. Co., Inc. [distributor: 1984.

7. Kubota, N., A new interpretation of metastable zone widths measured for unseeded solutions. J. Cryst. Growth 2008, 310 (3), 629-634.

8. Sangwal, K., Novel Approach to Analyze Metastable Zone Width Determined by the Polythermal Method: Physical Interpretation of Various Parameters. Cryst. Growth Des. 2009, 9 (2), 942-950.

9. Threlfall, T. L.; De'Ath, R. W.; Coles, S. J., Metastable Zone Widths, Conformational Multiplicity, and Seeding. Org. Process Res. Dev. 2013, 17 (3), 578-584.

10. Nagy, Z. K.; Fujiwara, M.; Woo, X. Y.; Braatz, R. D., Determination of the Kinetic Parameters for the Crystallization of Paracetamol from Water Using Metastable Zone Width Experiments. Ind. Eng. Chem. Res. 2008, 47 (4), 1245-1252.

11. He, G.; Tjahjono, M.; Chow, P. S.; Tan, R. B. H.; Garland, M., In Situ Determination of Metastable Zone Width Using Dielectric Constant Measurement. Org. Process Res. Dev. 2010, 14 (6), 1469-1472.

12. O'Grady, D.; Barrett, M.; Casey, E.; Glennon, B., The effect of mixing on the metastable zone width and nucleation kinetics in the anti-solvent crystallization of benzoic acid. CHEM ENG RES DES 2007, 85 (7), 945-952.

13. Boyd, S.; Back, K.; Chadwick, K.; Davey, R. J.; Seaton, C. C., Solubility, metastable zone width measurement and crystal growth of the 1: 1 benzoic acid/isonicotinamide cocrystal in solutions of variable stoichiometry. J. Pharm. Sci. 2010, 99 (9), 3779-3786.

14. Kadam, S. S.; Kulkarni, S. A.; Coloma Ribera, R.; Stankiewicz, A. I.; ter Horst, J. H.; Kramer, H. J., A new view on the metastable zone width during cooling crystallization. Chem. Eng. Sci. 2012, 72, 10-19. 15. Kubota, N., Effect of sample volume on metastable zone width and induction time. J. Cryst. Growth 2012, 345 (1), 27-33.

16. Kulkarni, S. A.; Kadam, S. S.; Meekes, H.; Stankiewicz, A. I.; ter Horst, J. H., Crystal nucleation kinetics from induction times and metastable zone Widths. Cryst. Growth Des. 2013, 13 (6), 2435-2440.

17. Kobari, M.; Kubota, N.; Hirasawa, I., Simulation of metastable zone width and induction time for a seeded aqueous solution of potassium sulfate. J. Cryst. Growth 2010, 312 (19), 2734-2739. 
18. Kobari, M.; Kubota, N.; Hirasawa, I., Deducing primary nucleation parameters from metastable zone width and induction time data determined with simulation. CrystEngComm 2013, 15 (6), 11991209.

19. Brandel, C.; ter Horst, J. H., Measuring induction times and crystal nucleation rates. Faraday Discuss. 2015, 179, 199-214.

20. Bhamidi, V.; Kenis, P. J.; Zukoski, C. F., Probability of Nucleation in a Metastable Zone: Induction Supersaturation and Implications. Cryst. Growth Des. 2017.

21. Byrappa, K.; Ohachi, T., Crystal growth technology. William Andrew: 2013.

22. Scheel, H. J.; Fukuda, T.; Wiley, J., Crystal growth technology. Wiley Online Library: 2003.

23. Tung, H.-H.; Paul, E. L.; Midler, M.; McCauley, J. A., Crystallization of organic compounds: an industrial perspective. Wiley-AIChE: 2009.

24. Pimpinelli, A.; Villain, J., Physics of crystal growth. Physics of Crystal Growth, by Alberto Pimpinelli and Jacques Villain, pp. 400. ISBN 0521551986. Cambridge, UK: Cambridge University Press, February 1999. 1999, 1.

25. Yang, H.; Rasmuson, Å. C., Nucleation of Butyl Paraben in Different Solvents. Cryst. Growth Des. 2013, 13 (10), 4226-4238.

26. Davey, R. J.; Back, K.; Sullivan, R., FD Crystal Nucleation from Solutions-transition states, rate determining steps and complexity. Faraday Discussions 2015.

27. Sullivan, R.; Davey, R.; Sadiq, G.; Dent, G.; Back, K.; Ter Horst, J.; Toroz, D.; Hammond, R., Revealing the Roles of Desolvation and Molecular Self-Assembly in Crystal Nucleation from Solution: Benzoic and p-Aminobenzoic Acids. Cryst. Growth Des. 2014, 14 (5), 2689-2696.

28. Lenka, M.; Sarkar, D., Determination of metastable zone width, induction period and primary nucleation kinetics for cooling crystallization of L-asparaginenohydrate. J. Cryst. Growth 2014, 408, 8590.

29. Yang, H., Relation between metastable zone width and induction time of butyl paraben in ethanol. CrystEngComm 2014, 17 (3), 577--586.

30. Yang, H., Reply to the "Comment on 'Relation between metastable zone width and induction time of butyl paraben in ethanol'" by L.-D. Shiau, CrystEngComm, 2015, 17, DOI: 10.1039/C5CE00101C. CrystEngComm 2015, 17 (23), 4405-4407.

31. Yang, H., Relation between metastable zone width and induction time of butyl paraben in ethanol. CrystEngComm 2015, 17 (3), 577-586.

32. Shiau, L.-D.; Lu, T.-S., A model for determination of the interfacial energy from the induction time or metastable zone width data based on turbidity measurements. CrystEngComm 2014, 16 (41), 9743-9752.

33. Shiau, L.-D., Comment on "Relation between metastable zone width and induction time of butyl paraben in ethanol" by H. Yang, CrystEngComm, 2015, 17, 577. CrystEngComm 2015.

34. Shiau, L.-D., The influence of solvent on the pre-exponential factor and interfacial energy based on the metastable zone width data. CrystEngComm 2016, 18 (34), 6358-6364.

35. Shiau, L.-D., Comparison of the interfacial energy and pre-exponential factor calculated from the induction time and metastable zone width data based on classical nucleation theory. J. Cryst. Growth 2016, 450, 50-55.

36. Zhang, Y.; Li, Z., Effects of Cooling Rate, Saturation Temperature, and Solvent on the Metastable Zone Width of Triethanolamine Hydrochloride. Ind. Eng. Chem. Res. 2011, 50 (10), 6375-6381.

37. Kim, K.-J.; Kim, M.-J.; Lee, J.-M.; Kim, S.-H.; Kim, H.-S.; Park, B.-S., Solubility, density, and metastable zone width of the 3-nitro-1, 2, 4-triazol-5-one+ water system. J CHEM ENG DATA 1998, 43 (1), 65-68.

38. Karel, M.; Nývlt, J.; Chianese, A., Crystallization of pentaerythritol I. Solubility, density and metastable zone width. Collection of Czechoslovak chemical communications 1994, 59 (6), 1261-1269. 
39. Kim, K.-J.; Mersmann, A., Estimation of metastable zone width in different nucleation processes. Chem. Eng. Sci. 2001, 56 (7), 2315-2324.

40. Nordström, F. L.; Svärd, M.; Rasmuson, Å. C., Primary nucleation of salicylamide: the influence of process conditions and solvent on the metastable zone width. CrystEngComm 2013, 15 (36), 7285-7297. 41. Liang, K.; White, G.; Wilkinson, D.; Ford, L. J.; Roberts, K. J.; Wood, W. M., Examination of the process scale dependence of L-glutamic acid batch crystallized from supersaturated aqueous solutions in relation to reactor hydrodynamics. Ind. Eng. Chem. Res. 2004, 43 (5), 1227-1234.

42. Chauhan, A.; Ramteke, R.; Eipeson, W., Properties of ascorbic acid and its applications in food processing: a critical appraisal. Journal of food science and technology 1998, 35 (5), 381-392.

43. Haworth, W. N., The Structure of Carbohydrates and of Vitamin C. PA Norstedt: 1938.

44. Shalmashi, A.; Eliassi, A., Solubility of L-(+)-ascorbic acid in water, ethanol, methanol, propan-2ol, acetone, acetonitrile, ethyl acetate, and tetrahydrofuran from (293 to 323) K. J CHEM ENG DATA 2008, 53 (6), 1332-1334.

45. Wierzbowska, B.; Hutnik, N.; Piotrowski, K.; Matynia, A., Continuous Mass Crystallization of Vitamin C in I(+)-Ascorbic Acid-Ethanol-Water System: Size-Independent Growth Kinetic Model Approach. Cryst. Growth Des. 2011, 11 (5), 1557-1565.

46. Yang, H.; Rasmuson, Å. C., Solubility of Butyl Paraben in Methanol, Ethanol, Propanol, Ethyl Acetate, Acetone, and Acetonitrile. J. Chem. Eng. Data 2010, 55 (11), 5091-5093.

47. Omar, W.; Mohnicke, M.; Ulrich, J., Determination of the solid liquid interfacial energy and thereby the critical nucleus size of paracetamol in different solvents. Cryst. Res. Tech. 2006, 41 (4), 337343.

48. Teychené, S.; Biscans, B., Nucleation Kinetics of Polymorphs: Induction Period and Interfacial Energy Measurements. Cryst. Growth Des. 2008, 8 (4), 1133-1139.

49. Jiang, S.; ter Horst, J. H., Crystal Nucleation Rates from Probability Distributions of Induction Times. Cryst. Growth Des. 2010, 11 (1), 256-261.

50. Mitchell, N. A.; Frawley, P. J., Nucleation kinetics of paracetamol-ethanol solutions from metastable zone widths. J. Cryst. Growth 2010, 312 (19), 2740-2746.

51. Mealey, D.; Croker, D. M.; Rasmuson, A., Crystal nucleation of salicylic acid in organic solvents. CrystEngComm 2015.

52. Davey, R. J.; Back, K. R.; Sullivan, R. A., Crystal nucleation from solutions - transition states, rate determining steps and complexity. Faraday Discuss. 2015, 179, 19.

53. Wallqvist, A.; Berne, B., Molecular dynamics study of the dependence of water solvation free energy on solute curvature and surface area. The Journal of Physical Chemistry 1995, 99 (9), 2885-2892. 54. Kulkarni, S. A.; Meekes, H.; Ter Horst, J. H., Polymorphism control through a single nucleation event. Cryst. Growth Des. 2014, 14 (3), 1493-1499. 